\title{
EXPERIMENTAL INVESTIGATION \& ANALYSIS OF HEA TRANSFER CHARACTERISTICS IN AUTOMOTIVE MMC DISC BRAKE UNDER STEADY STATE AND DYNAMIC CONDITIONS
}

DOI : 10.36909/jer.ICIPPSD.15527

\author{
Agarwal A.*, Molwane O.B.**, Letsatsi M.T.** \\ *Department of Mechanical Engineering, FET, University of Botswana, Gaborone, Botswana. \\ **Department of Industrial Design \& technology, FET, University of Botswana, Gaborone, \\ Botswana.
}

*Corresponding Author: agarwala@ub.ac.bw

\begin{abstract}
During braking process, the kinetic energy of vehicle reduces and gets converted in thermal energy due to friction between disk and brake pads. The disk brake is used to retard the motion of vehicle by pressing brake pads against disk rotors. The frequent braking or panic braking results in overheating of brake disks which may result in brake fade. It is therefore essential to test newer materials which are more effective and possess better heat transfer characteristics than conventional cast iron material. The current research investigates the application of $\mathrm{Al}$ MMC material for ATV disk brake using experimental and numerical techniques. The numerical analysis is conducted on both conventional cast iron and Al MMC disk brake under steady state conditions and dynamic conditions. The dynamic condition testing involved testing of disk brake with externally flowing air at $2.5 \mathrm{~m} / \mathrm{s}$ and $5 \mathrm{~m} / \mathrm{s}$ using techniques of Computational Fluid Dynamics (CFD). The CAD model of ATV disk brake is developed in Creo design software and CFD analysis is conducted using ANSYS CFX. The turbulence model used for analysis is RNG k-epsilon. The temperature and heat flux are determined for disk brake under steady state and dynamic conditions. The results have shown that disk brake made from Al MMC possess better heat transfer characteristics as compared to conventional cast iron and cooling time also reduces with increase in external air speed.
\end{abstract}

Key words: Disc brake; finite element method; brake fade; heat transfer; CFD. 


\section{INTRODUCTION}

The disk brake is used to retard the motion of vehicle. It comprises of disk rotor, brake pad and calipers (Abrar Ahmed et al., 2020). During braking process, the calipers squeeze the brake pad against disk rotor which reduces rotational speed of disk rotor connected to front axle/rear axle wheel or both. During the process, the kinetic energy of vehicle is converted into thermal energy due to friction between brake pads and disk. During panic braking or hard braking the brakes may become too hot which causes brake fade. The components of disk brake are shown in figure 1.

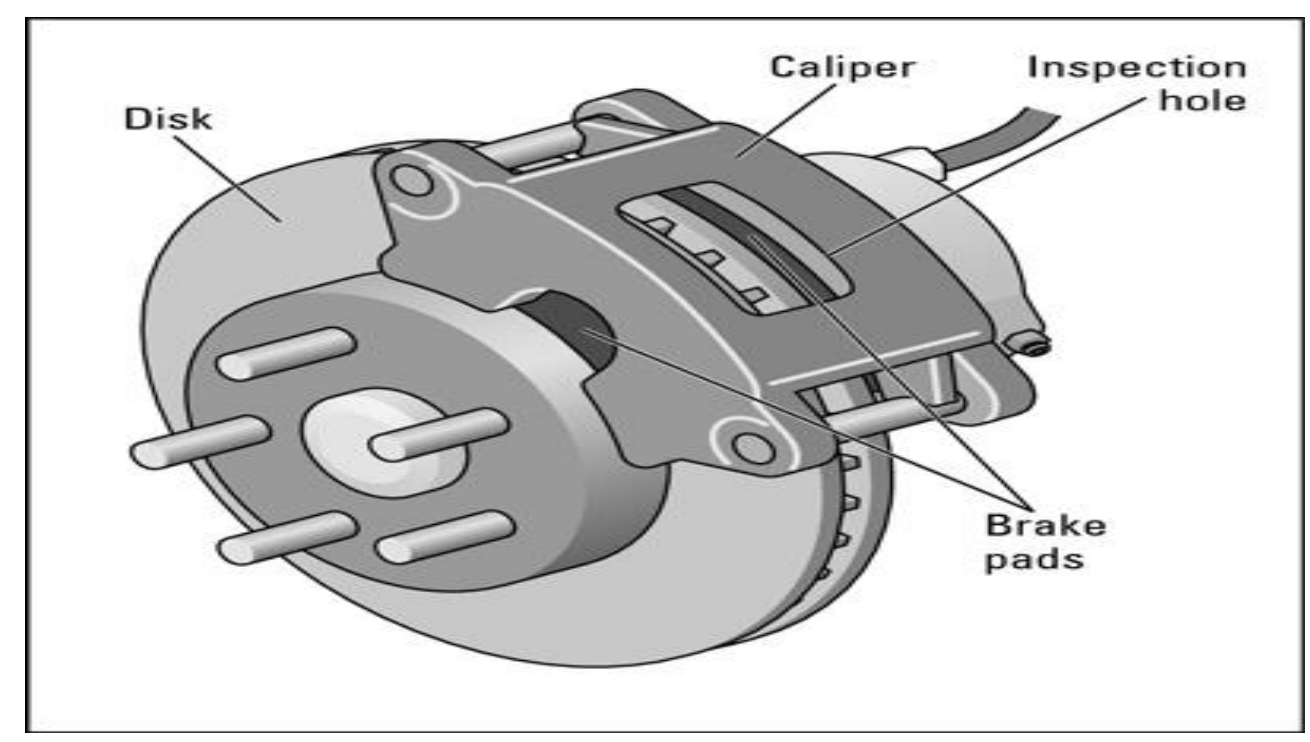

Figure 1 Components of disk brake (Sclar n.d.)

Grześ (2009) has conducted transient thermal analysis on solid disk brake during emergency braking. Two-dimensional model was developed, and parabolic conduction equation is used. The findings have shown that rotating speed of disk and contact pressure has significant effect on temperature of disc brake. Rahim, Bakar, and Ouyang (2007) has conducted contact analysis on four different models with each model having different complexities. The findings have shown that contact pressure effects the thermal stress and strain generated on disk brake. The design engineers should consider contact pressure as one of the important criteria for design of disk brake.

Nouby, Mathivanan, and Srinivasan (2010) has worked on integration of CAE with statistical regression. The vibrational frequencies of disk brake are determined from eigenvalue analysis. The design of experiments (DOE) is conducted to determine the effect of slot width, brake thickness and chamfer distance on output parameters. 
Bazdar, Kazemzadeh, and Niaki (2015) has conducted study to identify the variations in multistage manufacturing processes through integration of the FID analysis. The effectiveness of proposed method has been demonstrated by considering a case study in an automotive industry. Liu et al. (2007) has investigated the factors affecting brake squeal using ABAQUS simulation software. The results have shown that hydraulic pressure, rotational velocity, and pad bending vibration has significant effect on brake squeal. Pohane and Choudhari (2011) has conducted FEA analysis on solid and ventilated disk brake to under static loading conditions. The parameters assessed are equivalent stress and thermal stress. The FEA analysis results have shown that ventilated disk brake performed better than solid disk brakes. Manivanna Boopathi and Abudhahir (2015) has conducted a comprehensive research study to control the wheel slip using GA based fuzzy inference system. The simulation-based approach shows good results in desired level during braking and acceleration.

Mazidi et al. (2011) has conducted numerical analysis on disk brake using implicit method. The analysis undertook the effect of various parameters like contact pressure, vehicle velocity, dimensions of disk brake components and duration of braking. Thilak et al. (2011) has worked on application of lighter material for disk brake application using FEA analysis. The transient thermal analysis have shown that S2 glass fibre and aluminum composites are better than grey cast iron (Manickam et al., 2015). Chavan and Apte (2008) has conducted FEA analysis of disc brake using ABAQUS software. The numerical analysis was conducted under brake fade conditions and by axisymmetric modelling technique. The findings have shown effect of contact pair between brake pads and disk on temperature and heat flux generation. Kim et al. (2019) investigated the effects of the stiffness of exterior panels on customer satisfaction extensively in the field of affective automotive engineering. Proposed found to describe the mechanical properties of the panels. Cao et al. (2003) has conducted vibration analysis on disc brake to determine the mode shapes and natural frequencies of disk brake. The unstable natural frequencies determined from modal analysis are in close agreement with experimental analysis. Jung et al. (2010) has conducted FEA analysis on disk brake with two pads rotating at $1400 \mathrm{rpm}$. The coupled structural thermal analysis is conducted to determine thermal stresses. The results from FEA analysis are verified with experimental results.

The existing research is based on thermal and structural analysis of disc brake using fibre or other materials, but no research is conducted in application of MMC's for disc brake materials under steady and dynamic loading conditions. The conventional cast iron material has low heat dissipation capacity which results in brake fade. To improve heat dissipation capacity of disc 
brake, the conventional cast iron material needs to be replaced with more durable material having better thermo mechanical characteristics. The current research investigates the application of $\mathrm{Al} \mathrm{MMC} \mathrm{material} \mathrm{for} \mathrm{automotive} \mathrm{disc} \mathrm{brake.} \mathrm{As} \mathrm{the} \mathrm{brakes} \mathrm{are} \mathrm{applied} \mathrm{under}$ dynamic conditions (i.e., when vehicle is moving) it becomes essential to investigate the effect of moving air on temperature and heat dissipation of disc brake. So, to simulate this dynamic condition on our numerical analysis, we have analysed disc brake under external air flow conditions at both low-speed conditions and high-speed conditions.

For low-speed conditions relative velocity between air and vehicle is taken to be $2.5 \mathrm{~m} / \mathrm{sec}$ and for high-speed conditions the relative velocity is taken to be at $5 \mathrm{~m} / \mathrm{sec}$. The "CAD model of disc brake is developed in Creo design software and analysed using ANSYS CFX software (Agarwal, Molwane, and Marumo, 2020).

\section{METHODOLOGY}

The analysis involves experimental testing and numerical analysis. The numerical analysis is conducted for both steady state and dynamic state (i.e., external air velocity). The CAD model of wheel and disk brake rotor is developed in Creo design software as shown in figure 2 . The dimensions of disk brake are taken from ATV guide.

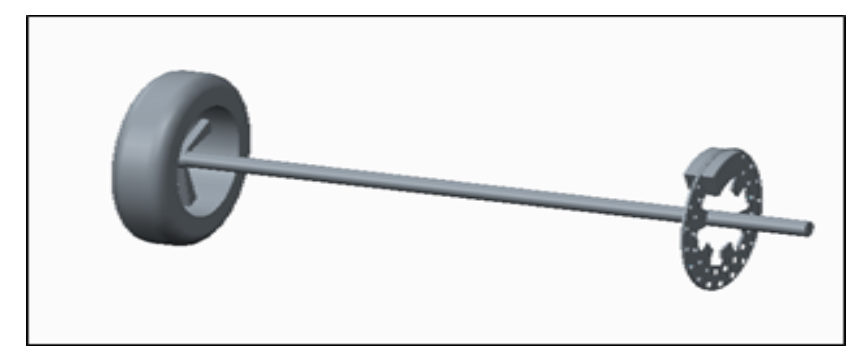

Figure $2 \mathrm{CAD}$ model of disk brake with shaft and wheel

The experimental testing is conducted by rotating wheel using lathe chuck. The brakes on disk brake are applied mechanically when wheel is rotating at specific RPM. The temperature is measured using sensors. Figure 3 shows that experimental testing setup.

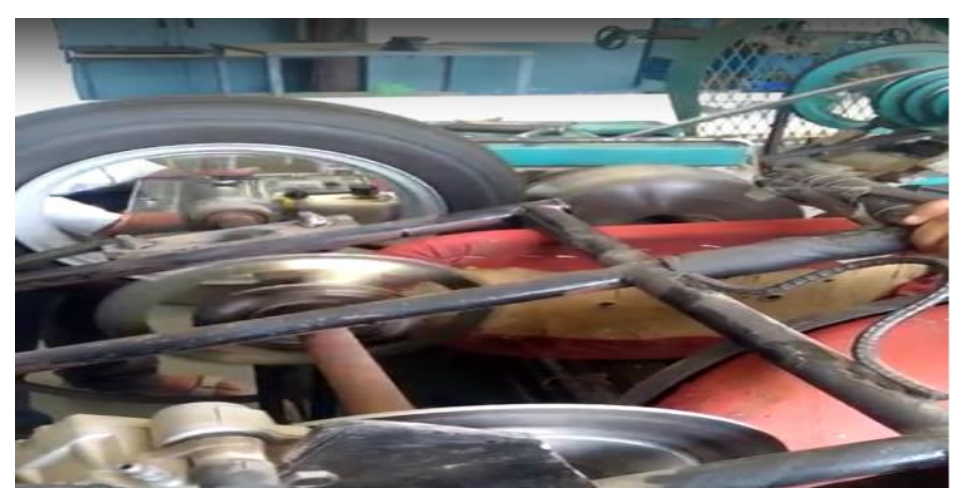


Figure 3 Experimental testing of disk brake

After conducting FEA analysis and experimental testing of disk brake for steady state conditions further analysis is conducted under transient thermal conditions. In transient thermal analysis CFD is used to determine the effect of external air flow conditions on heat dissipation from disk brake. The CAD model of ATV disc brake is imported in ANSYS design modeler to check for geometric errors as shown in figure 4. The model is discretized with tetrahedral elements (Agarwal et al., 2020) as shown in fig 4 (a). The number of elements generated is 31385 and number of nodes generated is 56855 . The thermal loads are applied on disc brake as shown in fig. 4 (b).

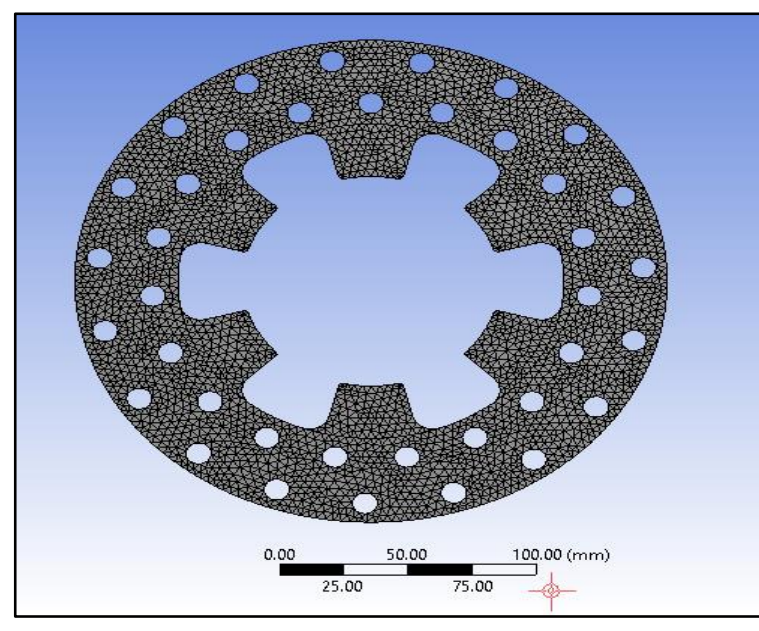

(a)

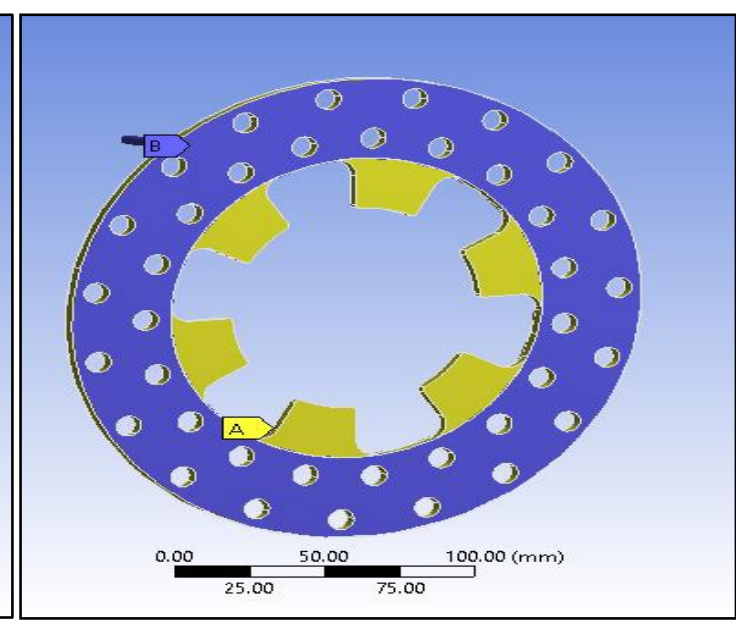

(b)

Figure 4 Imported CAD model of disk brake meshed model (a) and with thermal loads (b)

The thermal load calculation is based on conservation of energy. Where, Kinetic Energy = Thermal Energy $=1 / 2 \mathrm{I} \square^{2} \quad$ Braking time $=0.8$ second Braking Power $=$ Thermal Energy $/$ Time, Braking Power $=15.81 \mathrm{~J}$, Heat Flux $=$ Braking Power $/$ Area of Rubbing Surface $=385.6$ $\mathrm{W} / \mathrm{M}^{2}$, Heat Transfer Coefficient (Cast Iron to Air) $=7.9 \mathrm{~W} / \mathrm{m}^{2}$

Heat Transfer Coefficient (Al MMC To Air) $=90.3 \mathrm{~W} / \mathrm{m}^{2}$

Further analysis is conducted using Computational Fluid Dynamics to predict the heat flux and temperature profile under air flow conditions. The imported CAD model of disc brake is placed inside enclosure of $1 \mathrm{~m}^{*} 1 \mathrm{~m}^{*} .5 \mathrm{~m}$. The enclosure will define computational domain for the CFD analysis. Due to complexity of the geometry the domain is then meshed with 
tetrahedral elements. The meshing is done with medium size function, and inflation set to 1.2.

Fig.5 (a) shows disk brake and enclosure while the meshed model is shown in fig. 5(b).

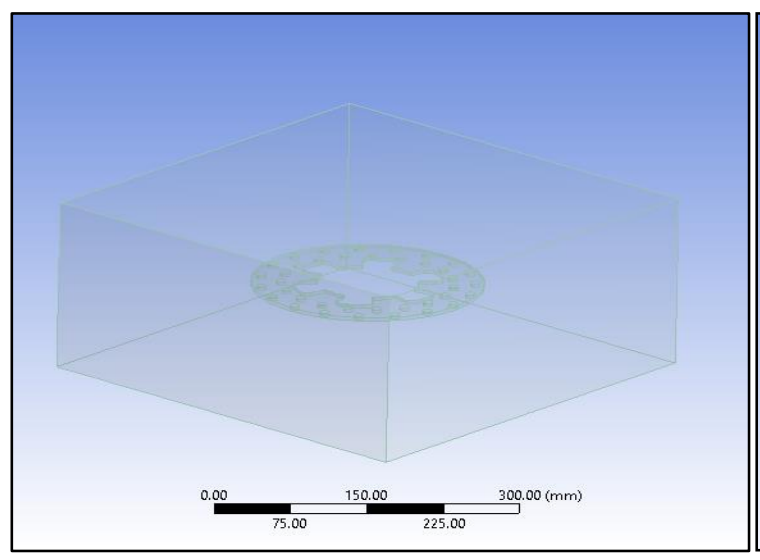

(a)

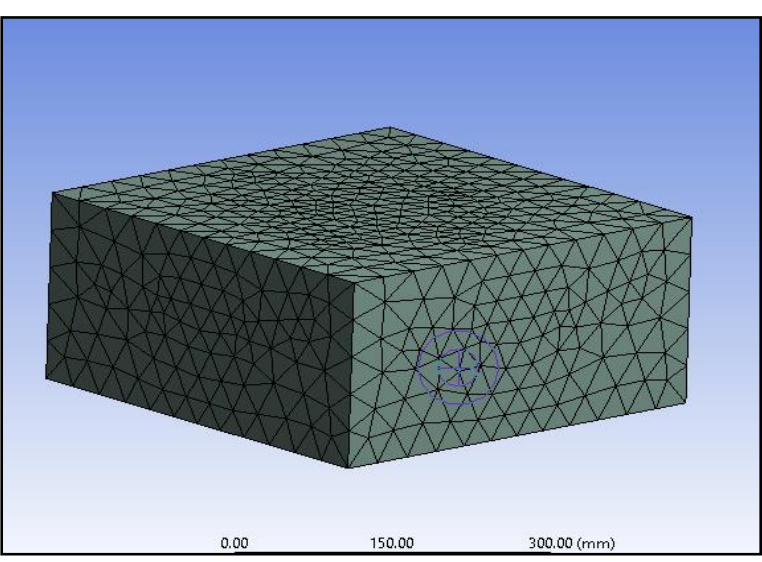

(b)

Figure 5 Computational domain model disk brake and enclosure (a) and meshed model (b)

The setup involves defining domain which is fluid domain for air and solid domain for cast iron. The reference pressure is set to $1 \mathrm{~atm}$ and turbulence model is set to RNG k-epsilon (Agarwal and Mthembu 2020). The CFD analysis is conducted at 2 different air velocities i.e., $2.5 \mathrm{~m} / \mathrm{s}$ and $5 \mathrm{~m} / \mathrm{s}$. The loads and boundary conditions are shown in figure 6 .

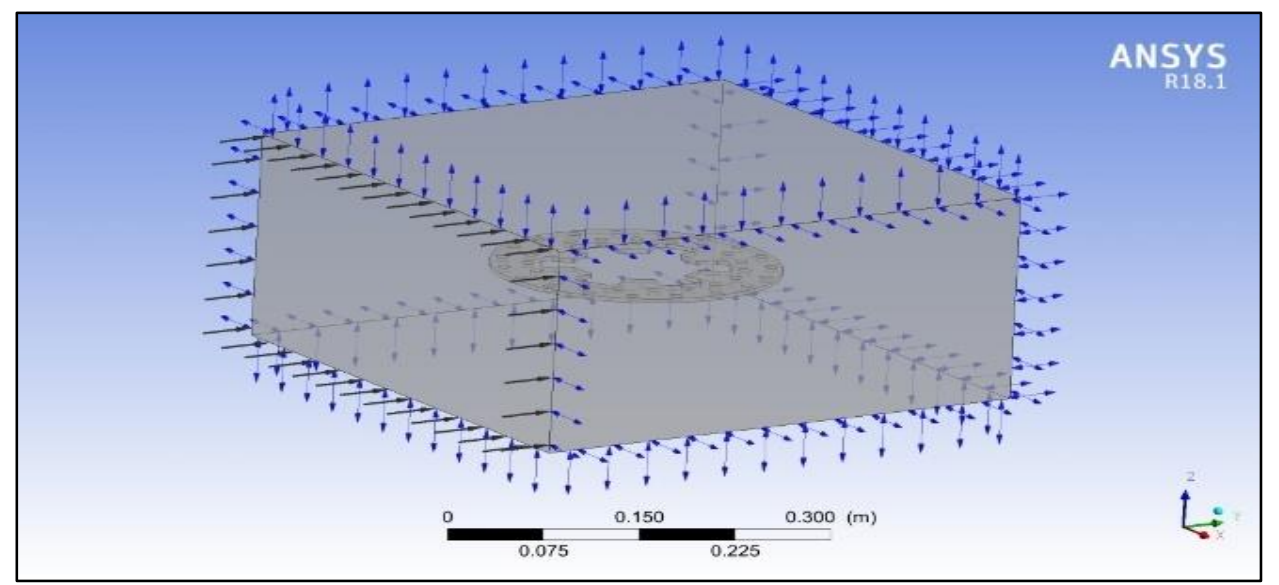

Figure 6 Loads and boundary conditions.

\section{RESULT AND DISCUSSION}

After defining loads and boundary condition, the steady state analysis is run to determine temperature and heat flux. The temperature profile of cast iron shows maximum temperature of disk brake reaches to $134^{\circ} \mathrm{C}$ which is observed on outer regions of disk whereas the inner regions of disk have minimum temperature of $128^{\circ} \mathrm{C}$. The red colored zone is the surface on which brake pad rubs against the disk and therefore it has maximum temperature. The 
temperature plot and heat flux plot for grey cast iron are shown in fig.7 (a) and fig.7 (b) respectively.

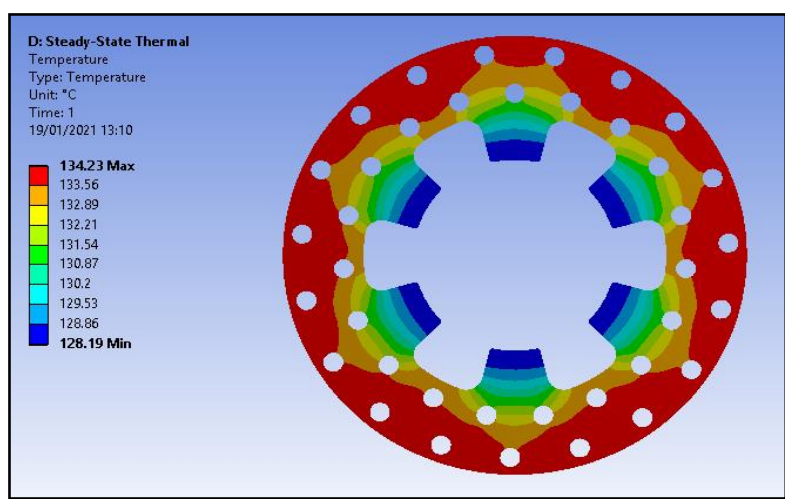

(a)

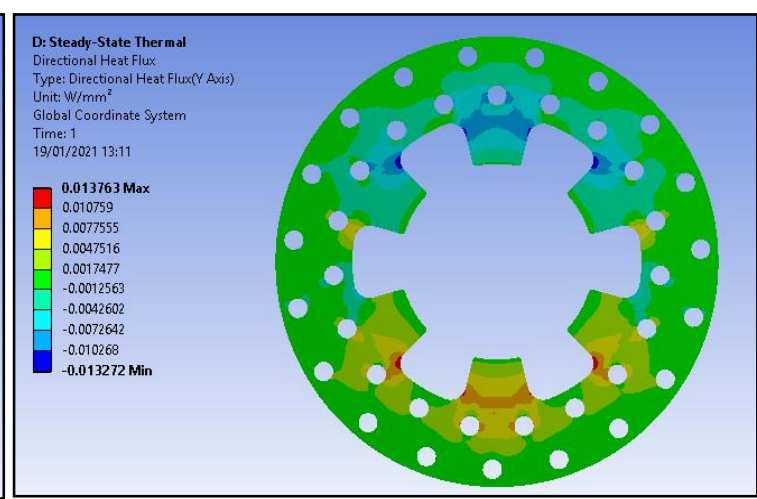

(b)

Figure 7 Plots for grey cast iron, temperature plot (a) and heat flux (b)

The temperature plot and heat flux plot for Al MMC disc brake are shown in fig. 8 (a) and fig. 8 (b), respectively.

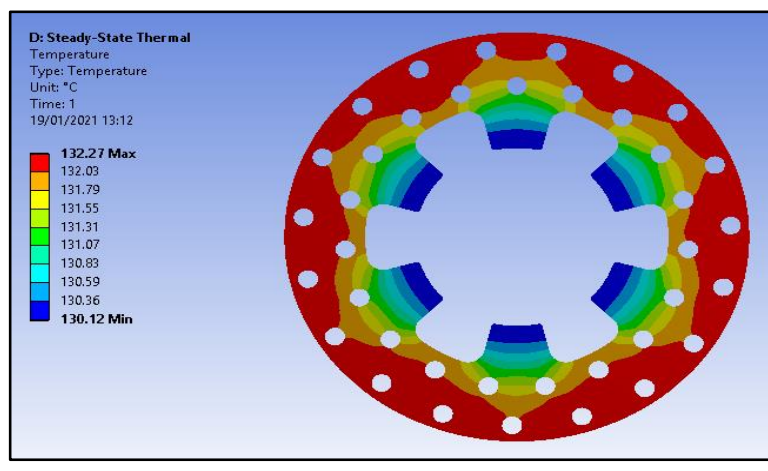

(a)

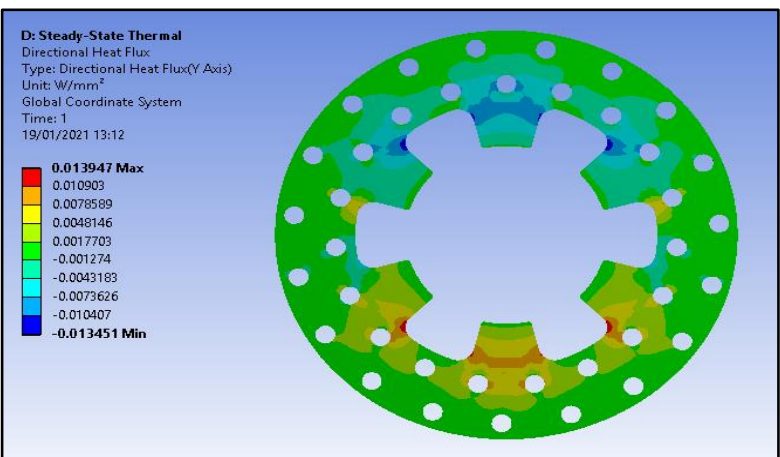

(b)

Figure 8 Plots for Al MMC, temperature plot (a) and heat flux (b)

The heat flux plot obtained for cast iron shows higher magnitude at the corner regions. The maximum directional heat flux along upward direction is $.013763 \mathrm{~W} / \mathrm{mm}^{2}$. The temperature profile of AL MMC disc brake shows maximum temperature of disk brake reaches to $132^{\circ} \mathrm{C}$ which is lower than that of cast iron and is observed on outer regions of disk whereas the inner regions of disk have minimum temperature of $130^{\circ} \mathrm{C}$. The red colored zone is the surface on which brake pad rubs against the disk and therefore it has maximum temperature. The heat flux plot shows higher magnitude at the corner regions and the maximum directional heat flux for $\mathrm{Al}$ MMC disc brake is $.0139 \mathrm{~W} / \mathrm{mm}^{2}$ along vertical direction. 
Further analysis is conducted under dynamic i.e., air flow conditions. The heat flux plot and temperature plot as shown in fig. 9 (a) and fig.9 (b), are generated for Al MMC disc brake operating at low air speed conditions i.e., $2.5 \mathrm{~m} / \mathrm{s}$.

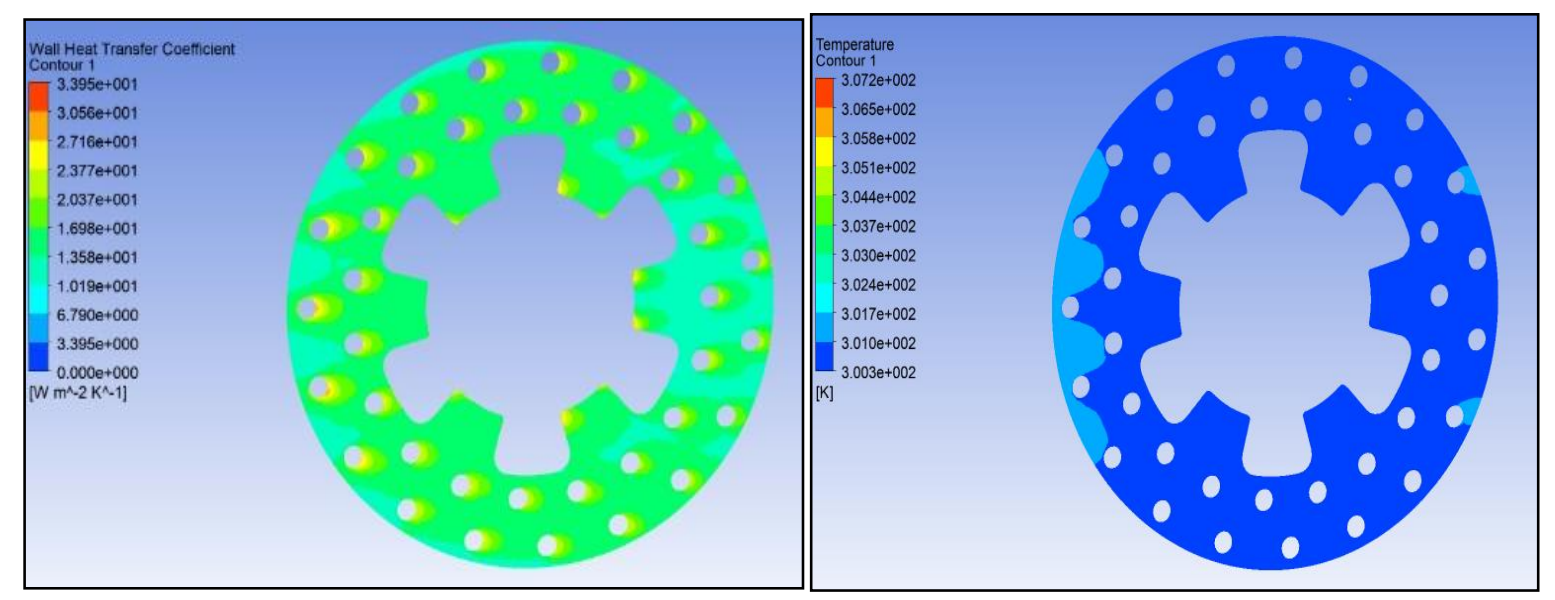

(a)

(b)

Figure 9 Dynamic condition for $\mathrm{Al} \mathrm{MMC} \mathrm{at} 2.5 \mathrm{~m} / \mathrm{s}$ heat flux plot (a) and temp. plot (b)

The temperature plot shows much lower temperature as compared to steady state analysis. Under dynamic conditions, the temperature in most of the regions of disk brake ranges from $303 \mathrm{~K}$ to $307 \mathrm{~K}$. The heat flux plot shows higher heat flow near ventilated holes (as shown by yellow colored region) as compared to other regions (as shown by green and blue colored regions. The heat flow under dynamic conditions is much higher than that in steady state conditions. The heat flux plot and temperature plot are generated for Al MMC disc brake operating at low air speed conditions i.e., $5 \mathrm{~m} / \mathrm{s}$ as shown in fig. 10 (a) and fig. 10 (b) respectively.

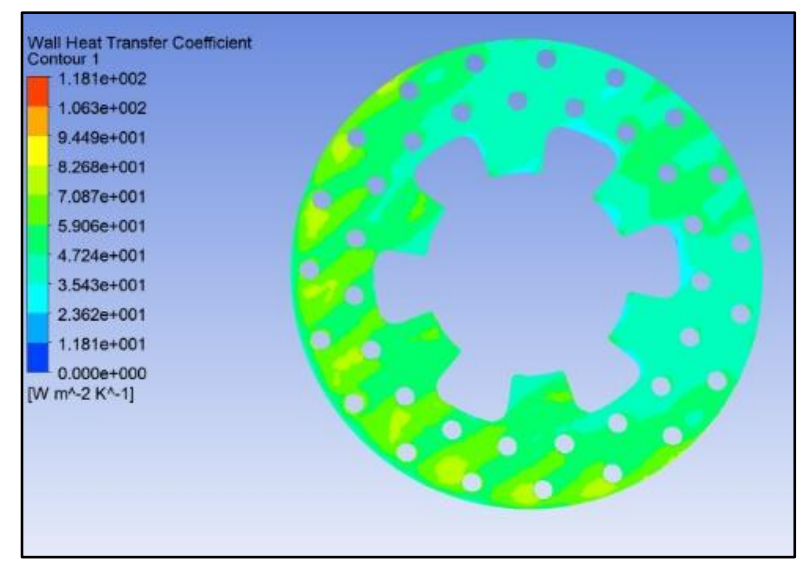

(a)

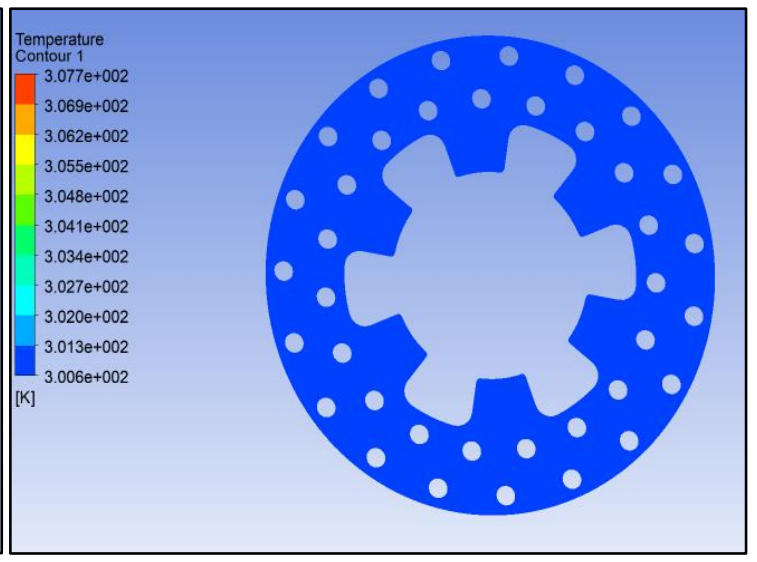

(b)

Figure 10 Dynamic condition for $\mathrm{Al} \mathrm{MMC}$ at $5 \mathrm{~m} / \mathrm{s}$ heat flux plot (a) and temp. plot (b) 
The heat flux plot shows maximum heat flux on windward zone i.e., left zone and bottom zone. The zone near holes has maximum heat flux of magnitude $94.49 \mathrm{~W} / \mathrm{m}-\mathrm{K}$ and other zones has heat flux of magnitude $23.62 \mathrm{~W} / \mathrm{m}-\mathrm{K}$. The temperature plot shows that the disc brake has almost uniform temperature throughout with magnitude of nearly $302 \mathrm{~K}$. Steady state analysis is indicated in table 1.

Table 1 Steady state analysis results

\begin{tabular}{|l|l|l|}
\hline Material & Temperature & Heat Flux \\
\hline Grey Cast Iron & $134^{0} \mathrm{C}$ & $0.01376\left(\mathrm{~W} / \mathrm{mm}^{2}\right)$ \\
\hline Al MMC & $132^{\circ} \mathrm{C}$ & $0.01394\left(\mathrm{~W} / \mathrm{mm}^{2}\right)$ \\
\hline
\end{tabular}

The comparison plot of temperature and heat flux is obtained for steady state conditions and is shown in figure 11 and figure 12, respectively. The temperature comparison shows that AlMMC disk brake has lower maximum temperature as compared to grey cast iron.

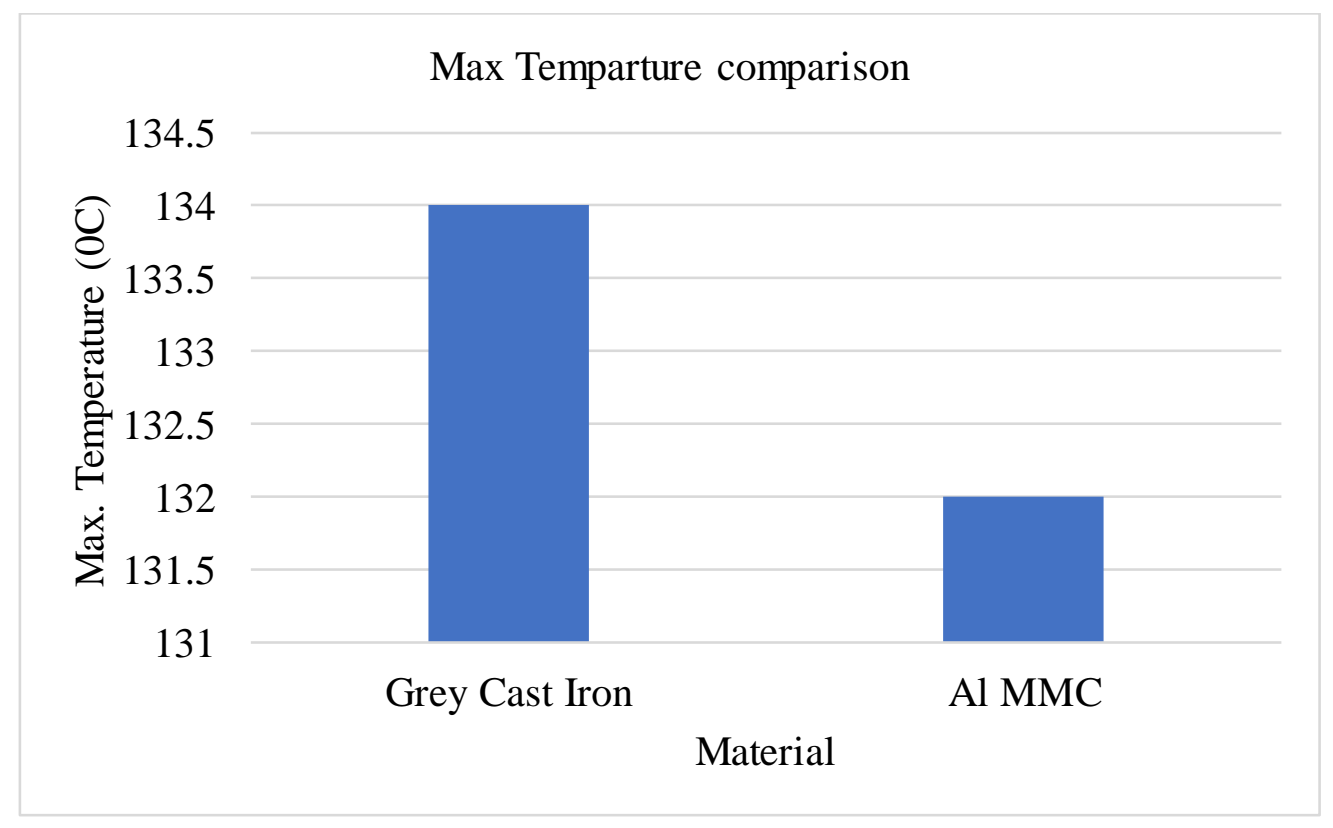

Fig. 11: Temperature comparison under steady state 


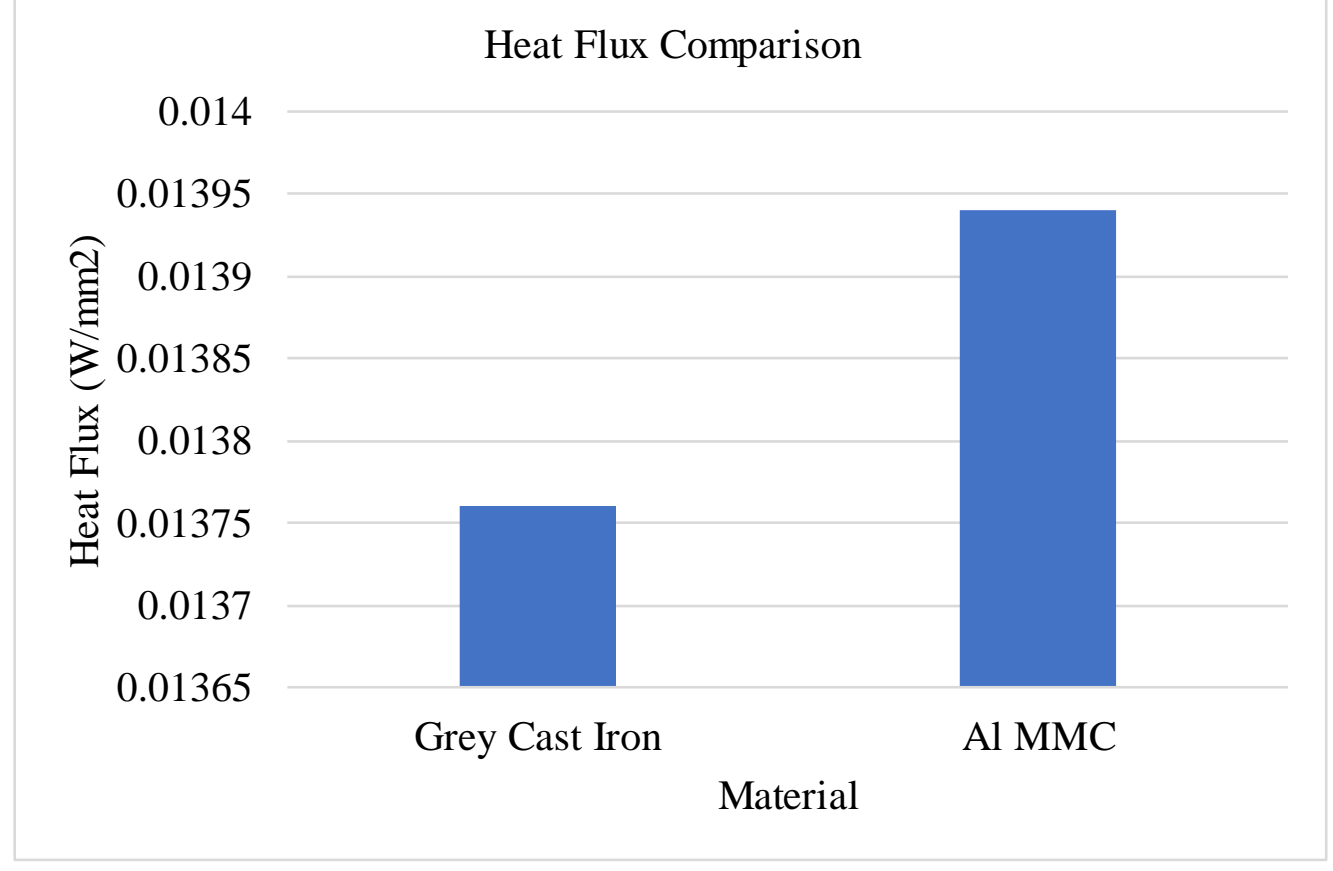

Fig. 12: Heat flux comparison under steady state

The heat flux (which indicates the heat flow) comparison plot shows Al MMC has higher heat flow against grey cast iron which shows that $\mathrm{Al}$ MMC disc brake has much better heat dissipation characteristics.

\section{CONCLUSION}

The steady state thermal analysis and dynamic analysis (under external air flow conditions) of ATV disc brake is conducted to determine to heat flow and temperature profile. The CFD results have shown that cooling time of disk brake significantly reduces with increase in external air speed. At $2.5 \mathrm{~m} / \mathrm{s}$, the disc brake cooled and reached to steady state within 4 secs and at $5 \mathrm{~m} / \mathrm{s}$ the disc brake cooled within 2.8 secs. The steady state analysis shows that $\mathrm{Al}$ MMC has higher heat flow against grey cast iron which shows that Al MMC disc brake has much better heat dissipation characteristics. The results obtained from experimental testing are in close agreement with numerical results.

\section{REFERENCES}

Abrar Ahmed, A. S., V. Ayush Kumar, S. Gokul, P. Vijay, and C. Parthasarathy. 2020. Design and Analysis of Disc Brake Rotor Using Different Profiles. International Journal of Engineering Applied Sciences and Technology 04(09):286-93.

Agarwal, A., O. B. Molwane, and R. Marumo. 2020. Design Optimization of Knuckle Stub Using Response Surface Optimization. Pp. 155-64 in Advances in Lightweight Materials and 
Structures, Singapore: Springer Singapore.

Agarwal, A. and L. Mthembu. 2020. CFD Analysis of Conical Diffuser under Swirl Flow Inlet Conditions Using Turbulence Models. Materials Today: Proceedings 27(2):1350-55.

Bazdar, Aliasghar, Reza Baradaran Kazemzadeh, and Seyed Taghi Akhavan Niaki. 2015. Variation Source Identification of Multistage Manufacturing Processes through Discriminant Analysis and Stream of Variation Methodology: A Case Study in Automotive Industry. Journal of Engineering Research 3(2):96-108.

Cao, Q., M. I. Friswell, H. Ouyang, J. E. Mottershead, and S. James. 2003. Car Disc Brake Squeal: Theoretical and Experimental Study. Materials Science Forum 440-441:269-76.

Chavan, Prashant and Amol Apte. 2008. Axisymmetric Analysis of Bolted Disc Brake Assembly to Evaluate Thermal Stresses. Abaqus India Regional Users Meet 1-7.

Grześ, P. 2009. Finite Element Analysis of Disc Temperature during Braking Process. Acta Mechanica et Automatica Vol. 3(4):36-42.

Jung, Seung-Pil, T. Park, J. Lee, W. Kim, and W. Chung. 2010. Finite Element Analysis of Themalelastic Instability of Disc Brakes. Lecture Notes in Engineering and Computer Science 2184.

Kim, Wonjoon, Donggun Park, Taebeum Ryu, and Myung Hwan Yun. 2019. Analysis of Customers' Satisfaction with Automobile Exterior Panel Stiffness: Focus on the Hood and Doors of Mid-Sized Sedan. Journal of Engineering Research (Kuwait) 7(2):281-97.

Liu, P., H. Zheng, C. Cai, Y. Y. Wang, C. Lu, K. H. Ang, and G. R. Liu. 2007. Analysis of Disc Brake Squeal Using the Complex Eigenvalue Method. Applied Acoustics 68(6):60315 .

Manickam, C., Jagadisan Kumar, A. Athijayamani, and Natesan Diwahar. 2015. Mechanical and Wear Behaviors of Untreated and Alkali Treated Roselle Fiber-Reinforced Vinyl Ester Composite. Journal of Engineering Research 3:1-13.

Manivanna Boopathi, A. and A. Abudhahir. 2015. Firefly Algorithm Tuned Fuzzy Set-Point Weighted PID Controller for Antilock Braking Systems. Journal of Engineering Research 3(2):79-94.

Mazidi, H., S. Jalalifar, S. Jalalifar, and J. Chakhoo. 2011. Mathematical Modeling of Heat Conduction in a Disk Brake System during Braking. Asian Journal of Applied Sciences 4(2):119-36. 
Nouby, M., D. Mathivanan, and K. Srinivasan. 2010. A Combined Approach of Complex Eigenvalue Analysis and Design of Experiments (DOE) to Study Disc Brake Squeal. International Journal of Engineering Science and Technology 1:254-71.

Pohane, Rajendra and R. G. Choudhari. 2011. DESIGN AND FINITE ELEMENT ANALYSIS OF DISC BRAKE. International Journal of Engineering Research \& Industrial Application 4(I):2011.

Rahim, A. B. D., A. B. U. Bakar, and Huajiang Ouyang. 2007. Prediction of Disc Brake Contact Pressure. 43(0):21-35.

Sclar, D. n.d. "How to Check Disc Brakes."

Thilak, V. M. M., R. Krishnaraj, M. Sakthivel, K. Kanthavel, M. .. Marudachalam, and R. Palani. 2011. Transient Thermal and Structural Analysis of the Rotor Disc of Disc Brake. International Journal of Scientific \& Engineering Research 2(8):2-5. 